Abstract

\title{
Use of a Zebrafish Model to Evaluate Toxicity of Schiff Base Complexes of Copper (II) and Zinc (II) as Possible Antineoplastic Agents ${ }^{\dagger}$
}

\author{
Claudia Cardozo ${ }^{1}$, Andreas Reiber 1,* and Veronica Akle ${ }^{2}$ \\ 1 Laboratory of chemistry of the inorganic-organic interfase, Chemistry Department, \\ Universidad de los Andes, Cra 1 № 18A - 12, 111711 Bogotá, Colombia \\ 2 Laboratory of Neuroscience and Circadian Rhythms, School of Medicine, Universidad de los Andes, \\ Cra 1 № 18A - 12, 111711 Bogotá, Colombia \\ * Correspondence: areiber@uniandes.edu.co \\ + Presented at the 2nd Molecules Medicinal Chemistry Symposium (MMCS): Facing Novel Challenges in \\ Drug Discovery, Barcelona, Spain, 15-17 May 2019.
}

Published: 7 August 2019

\begin{abstract}
Cancer continues to be one of the leading causes of death, according to the World Health Organization, and chemotherapy is its principal treatment. Organometallic complexes with copper (II) and zinc (II) with Schiff bases as ligand, capable of interacting with cancer cells' DNA under physiological conditions, may work as good chemotherapy agents because they are less toxic to healthy cells than to cancerous ones. In view of the above, this work focuses on obtaining new Schiff base ligands and their copper and zinc complexes and characterizing them by nuclear magnetic resonance, mass spectrometry, infrared spectroscopy, and other spectroscopic and spectrometric techniques. The objective is to evaluate the toxic activity of the new molecules using the fast proliferating cells of the zebrafish model during development. The toxicity test was performed in zebrafish embryos at $8,24,48$ and $72 \mathrm{~h}$ post fertilization, and a survival and malformation index were registered. Preliminary results show a dose-related effect of the designed Schiff ligands and complexes on the toxicity of the zebrafish embryo and larvae. The survival and malformation index are more severe when exposure occurs during early developmental stages, when cell division is higher due to rapid organization and growth of the new organism. This is a promising result, as the molecules might be cytotoxic to highly proliferating cells, as it occurs in cancer cells. This work represents one of the very few examples that use the zebrafish model to evaluate the cytotoxic activity of Schiff base complexes. Developing the animal model to test the effect of Schiff ligands and their complexes is an important first step to assess the effectiveness of new molecules as antineoplastic agents.
\end{abstract}

Keywords: Schiff bases; complexes; copper; zinc; zebrafish; antineoplastic; cancer

Conflicts of Interest: The authors declare no conflict of interest.

(C) 2019 by the authors. Licensee MDPI, Basel, Switzerland. This article is an open access article distributed under the terms and conditions of the Creative Commons Attribution (CC BY) license (http://creativecommons.org/licenses/by/4.0/). 